\title{
AN APPARATUS FOR CORING UNDISTURBED SAMPLES IN DEEP BOREHOLES
}

\author{
K. E. WIT \\ Institute for Land and Watermanagement Research, Wageningen, Netherlands ${ }^{1}$
}

Received for publicstion November 2, 1981

Sampling is an integral part of most physical sciences and especially in geological and soildrainage problems. The quality of the work depends largely upon the quality of the samples, and the use of core samples has long been recognized to be of considerable value, in that it makes available accurate information concerning the various particle and mass properties of the sediments.

The problem of taking core samples in boreholes below the ground-water table has occupied many investigators and has led to the construction of a great number of boring apparatuses, which, as described by Hvorslev (3), often differ only slightly in detail.

In general, the process of obtaining cores from coherent deposits presents few difficulties. By one means or another the core barrel is first pushed into the layer to be sampled and then pulled up. Often the core barrel is shut off and made air tight above the sample by means of a piston or ball valve. The friction resistance between sample and sample tube, as well as the cohesive force of the grains acting on each other, prevent core losses during the raising of the coring apparatus.

The maximum length of the cored sample is determined, among other factors, by the friction resistance and the diameter of the core barrel and sample tube, and by the characteristics of the layer sampled. In this connection, an apparatus was described by Kjelmann, Kalstenius, and Wager (4), in which the core barrel has such a low resistance to penetration that little deformation of the sample takes place.

1 The author is greatly indebted to J. E Upson of the United States Geological Survey for translating the original manuscript into English.
For taking samples from incoherent deposits, however, such apparatuses are unsuitable, because, upon raising the apparatus in the borehole, often an important part of the sample flows out of the sample tube. To prevent this outflow, various mechanical shutoffs of the underside of the core barrel have been constructed and applied. In most cases these shutoffs consist of metal straps or flaps that close over the opening of the core barrel when it is hauled up. Although this device serves to limit grain losses, the reliability of effective operation is rather slight. The chance of disturbing a sample is great, especially if the sample is from a sandy layer.

Nonmechanical devices that prevent the sample from flowing out of the sample tube were developed by Milton and Vargas and by Glossop [Hvorslev (3)], Bishop (2), and Van de Beld (1). In many of these methods, water in the sample is partially driven out by air before beginning to lift the core barrel. Driving out the water increases the tendency of the sample to cling to the wall of the sample tube and generates capillary forces within the sample that increase the internal friction. Partial de-watering of the sample is attained either by lowering the water level in the borehole or by forcing air into the sample from the underside of the core barrel.

This method disturbs the sample much less than mechanically closing off the core barrel. The effect of the partial de-watering depends on the degree to which it increases the friction between the sample and the wall of the sample tube, and the coherence of the sample. It is clear that the capillary forces aroused sometimes will not be adequate, for example in coarse sands containing fine gravel, so in these cases a mechanical shutoff of the underside of the core barrel is preferable. 


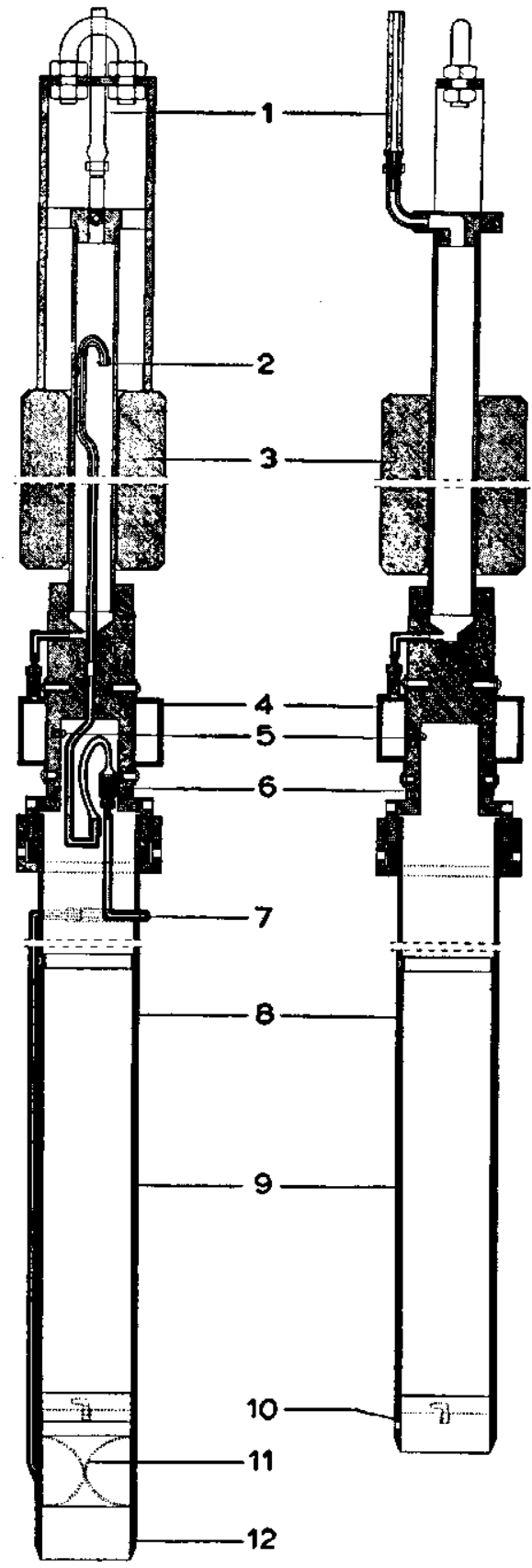

Fig. 1. Profile diagram of sampler with shoe $A$ (left) and shoe $B$ (right); the top of the apparatus turned 90 degrees and the tubes in the sampler head omitted: $(1)=$ air hose; $(2)=$ nylon cloth; $(\$)=$ steel weight; $(4)=$ rubber tire; $(5)=$ port; $(6)=$ sampler head; $(7)=$ air line; $(8)=$ outer barrel; $(9)=$ sampling tube; $(10)=$ shoe $B$ $(11)=$ rubber ring; (12) $=$ shoe $A$.
Because it did not seem possible to take samples with the existing core-boring apparatuses from layers of coarse sand to fine gravel without substantial core loss, and because just such layers occur over large areas in the deltaic deposits of The Netherlands, at depths that are important in many ground-water problems, a boring apparatus was constructed by which, from these coarse layers, complete core samples could be taken. A detailed description of the construction of this apparatus, together with details of its operation, is reported below.

\section{DESCRIPTION OF THE APPARATUS}

The apparatus that was developed and constructed is equally suitable for taking undisturbed samples in fine sandy and clayey deposits, in which only a shutoff of the upper side of the core barrel is adequate, and for taking samples in coarse sandy to fine gravelly sediments. For taking samples in the last-named deposits, a mechanical shutoff has been built which, in respect to core recovery, has produced very satisfactory results.

A eross section of the apparatus is given in figure 1, with cutting shoe $A$ (left), which can be closed off from the inside, and cutting shoe $B$ (right), which is used for coherent deposits. Moreover, in the right-hand drawing, the upper part of the apparatus has been given a quarter turn. In the right-hand diagram, the air line in the inner part of the sampler head is not reproduced. The difference, however, lies only in the cutting shoe used, in that most of the outer air line (left) is attached firmly to cutting shoe $A$. The inner air line remains in the sampler head when using either cutting shoe $A$ or cutting shoe $B$, and is merely shut off at the place where inner and outer air lines are coupled (in fig. 1 opposite notation 7).

The apparatus consists of the following parts (fig. 1):

(1) Rubber air hose connected to the inside of the sampler head and, at the other end, to both a vacuum and a pressure pump equipped with manometers (fig. 2).

(2) Nylon cloth through which the air is filtered before it passes into the thin air line.

(3) Steel weight fixed on the cable. The core barrel is driven into the ground by hoisting the weight with the cable and letting it fall.

(4) Rubber tire which can be inflated. This 
tire is in al small chamber with a perforated bottom.

(5) Outflow opening. As the core barrel penetrates into the ground, the displaced water flows off by way of two outflow openings (of which one is drawn in perspective), into the (hamber with a perforated bottom. When inflated, the rubber tire in this chamber closes off the outflow openings. This method of shutoff has the adrantage that, even though sand and silt got into the space, a complete shutoff is obtained. The rubber tire closes itself over the grains.

(6) Sampler head on which the core barrel an be attached.

(7) Air tube. This is connected with the pumps on one side (by way of the tubes in the sampler head and the rubber hose and with eutting shoce .1 on the other side. Fear item 7 (fig. 1) the air tube ean be uncoupled and shut off in atse rutting shoe if (with the greatest part of the outside air tube) is (exphangerd for cutting shoc $B$.

(8) Outer barrel. 'This is secured onto the sampler head by mouns of a swivel and, for airtight closure, a rubber washer. The core barrel is reamed out in the lowermost $312 \mathrm{~mm}$. of its total length of $600 \mathrm{~mm}$. The sampling tubes (an be inserted into the resulting space.

(9) Sampling lube. Made out of 1-mm.-thick zine with an inside diameter of $62 \mathrm{~mm}$. and a length of $300 \mathrm{~mm}$. It is prevented from falling out by the eutting shoe. $A$ number is stamped on the bottom end of the tube.

(10) Cutting shoe $B$, with a bayonet catch and

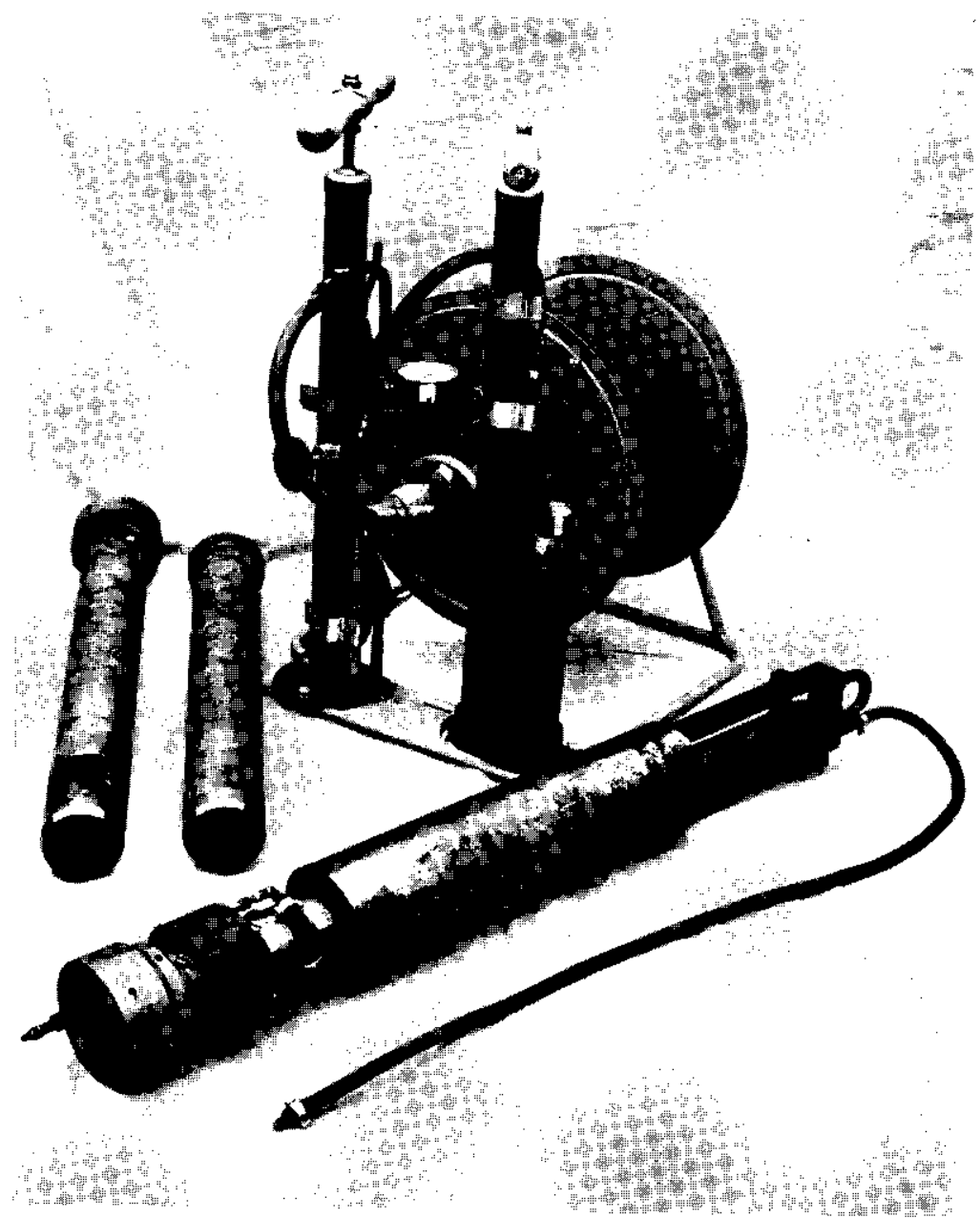

Ftci. 2. Wetails of coring rig. Reel for air hose, vacuum and pressure hand-pumps with manometers; two outer barrels with (left) shoo, $A$ and (right) shoe $B$; sampler head and steel weight. 
bolt serured to the corr barrel, 'This cutting shos is userd in clay, peat, and fine saml (either siltcontaining or not). After elosing off the outflow openings in the sampler head, the sample continues to adhere to the sampling tube. Whenever coring is done above the water table, the lowest part of the borehole must be filled with water before the aplparatus is brought in; otherwise, air would rome above the sample. In this last ease, elosing the sampler head has no effect, and there is a possibility that the sample will be pulled out of the sampling tube.

(11) Rubber ring. 'J'he largest part of the outer air tube is firmly secured to cutting shoe $A$. In the inner side of the eutting shoe is another rubber ring that can be inflated (in fig. 1 drawn in inflated condition).

(A)

(B)

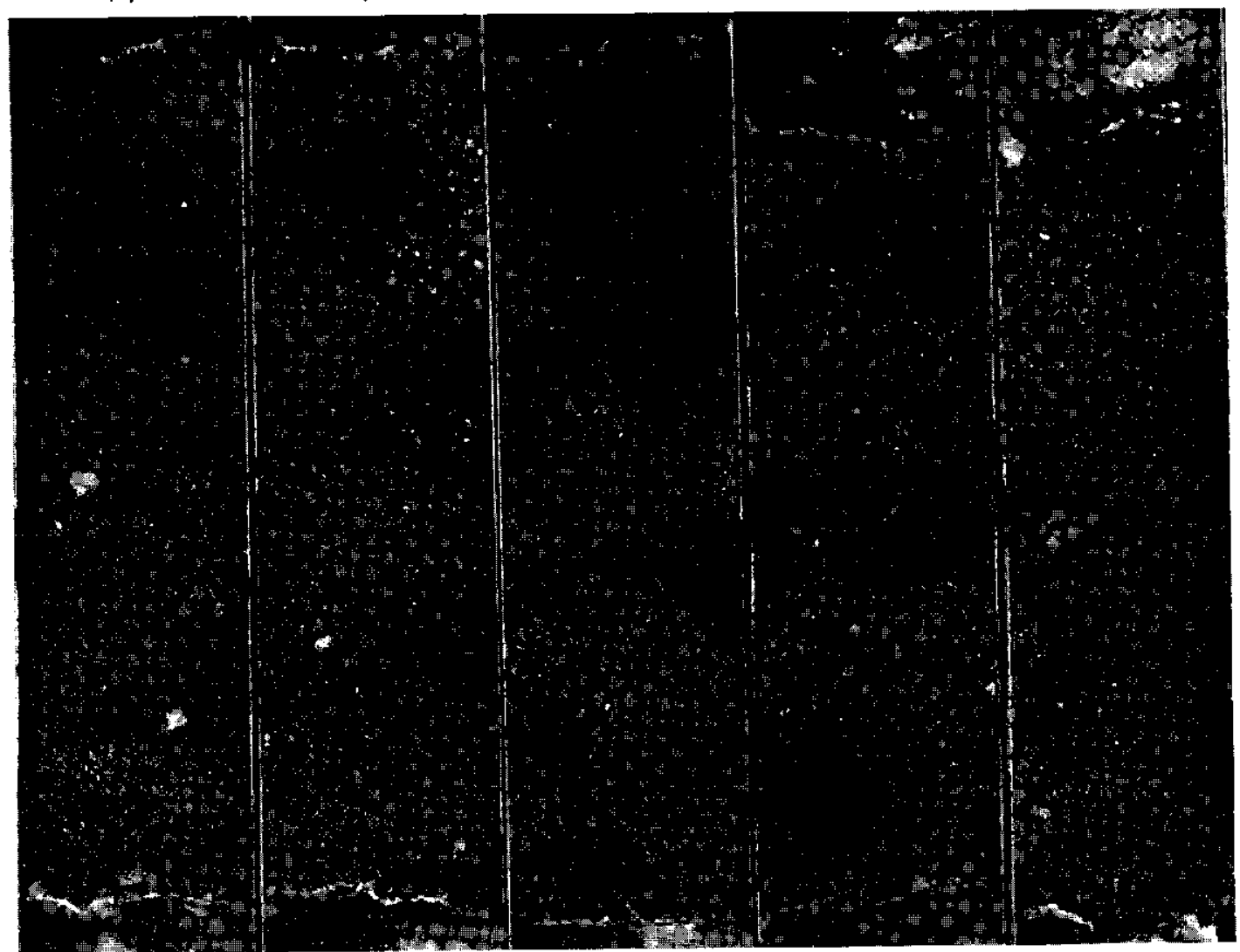

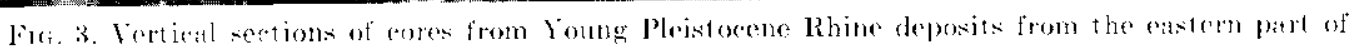

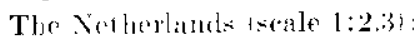
(A) $11+2(5.60-5.80)$
$k_{r}=22.7 \mathrm{~m} . / \mathrm{d}: \mathrm{s}$
(D) $M+5(7.10-7 \cdot 263$
$\mathrm{k} .=11.9 \mathrm{~m} . / \mathrm{d}: \mathrm{y}$

(12) Cutting shoe A. This cutting shoe with, in the upper part, the rubber ring, is used for sampling coarse sandy layers. Before coring is begun, the air is drawn up by the surtion pump so that the rubber ring lies flat against the inner side of the cutting shoe. The underpressure is maintained during coring. When the core barrel has reached the desired depth, air is pumped into the line. The outflow openings beromo completely shuts off the core barrel. The maximum prormissible pressure of the rubber tire in the housing is 3 atmospheres of pressure over and above the atmospherio pressure plus the pressure of the water column in the borehole; and of the rubber ring in the driving shoe, 2 atmospheres of overpressure. In overpressure closed and the rubber ring in the cutting sho 


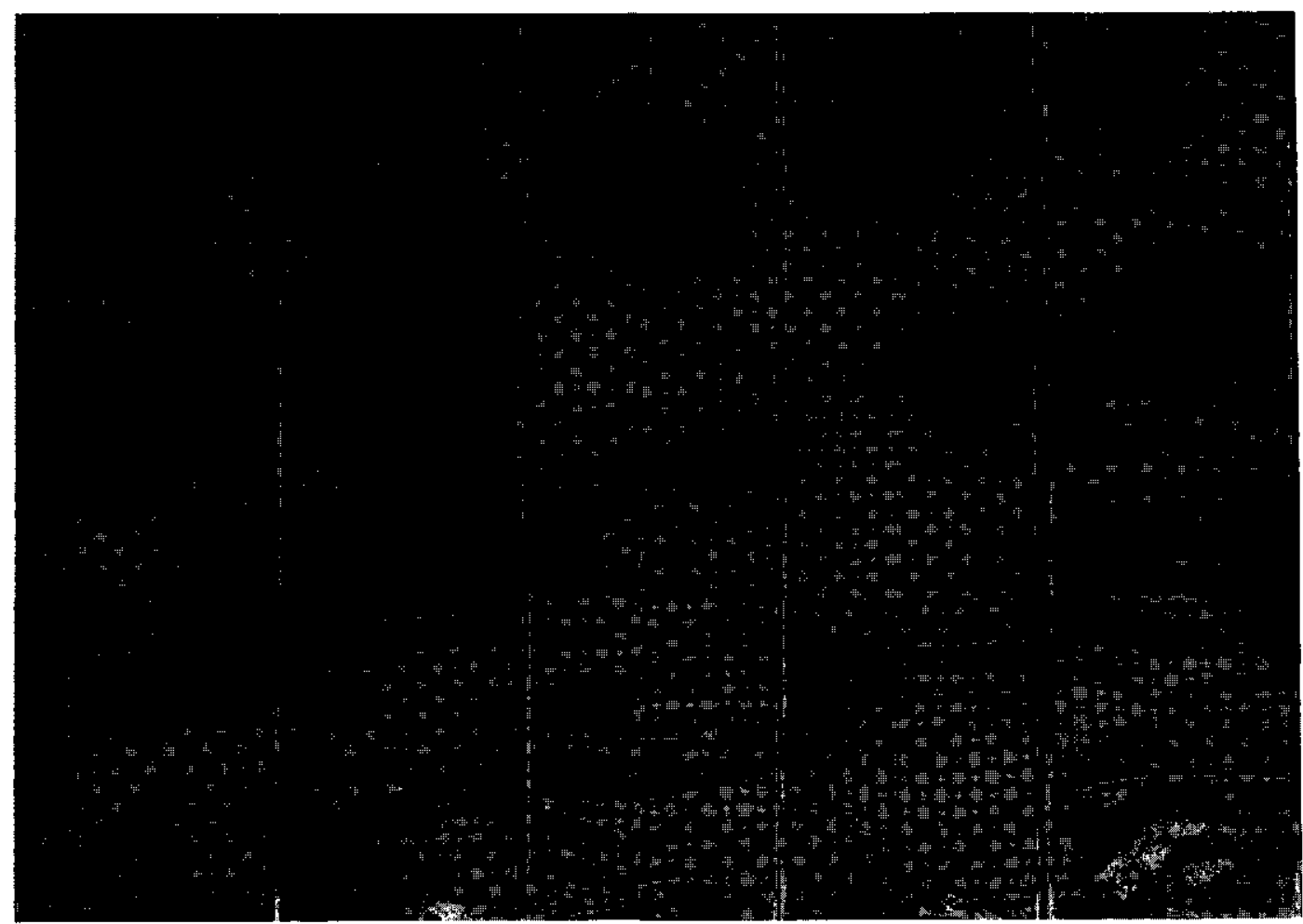

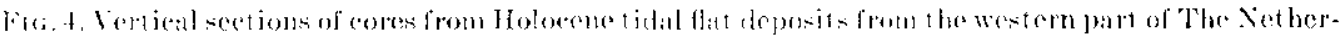
lamblo $(s,: 4)(1: 2.3)$ :
(A) h $: 32+(11.00) 11.21$,

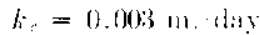
(B) 1,2325$)$ । 11.5011 .71 !
$d_{i,}=1.0 \mathrm{~m} 1 . / \mathrm{day}$
$\left.f_{i}=0.0 \mathrm{~b}\right) \mathrm{i} \mathrm{m} . / \mathrm{day}$
(C) h $320(12.0$ (N) 12.21)
$k_{.}=0.001 \mathrm{~m} . ; \mathrm{dity}$
(D) h $328 \mathrm{~s}, 13.0013 .21)$
$k_{i s}=1.33 \mathrm{~m} . / \mathrm{tan}$
$h_{:}=0.01 \mathrm{~m} . / \mathrm{daty}$
(E) h $3229(13.53) 13.71)$
$\left.k_{1}=11 \mathrm{i} .10\right)^{1} \mathrm{~m} . / \mathrm{day}$

of about 1 atmosphere will completely elose off the outflow ofenings as well as the bottom side of the eore batrel.

\section{OPHARTON OF THE APPARATUS}

The alpharatus (an be used for borings to a elepoth of not merte than 50 moteres. Heretofore, most borings to this apth lavet bean dome by the bailer-drilling methox. Although the apjouratus built is lasedul in this boring mothorl, some objestions are present in this combination. ('lean bailing of the boreholo produces some: difficultios whon stromgly flowing sands, among othol things, ale poresent. Is a result of this there is a possibility that the afparatus will romain sturk in the borehole. Most witisfactory results were athieved ly taking erose in eombination with abod flush borings. Brofore the sambule is takem, the borehole should be flushed rot ustil rear water anjerars at the surfiace.

In coring, the following joresdures are establishore:

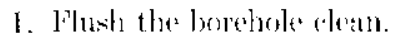

2. Place the simmble tube in the core basted.

3. Fisten eutting shoe I or cutting shoe $B$.

4. Hatng the apparatus in the rlrilling rig.

5. In using entting shos .1, draw the gubber ring in the rutting shor against the wall by vilelum (under pressure).

6. Lowere the aring apparatus (with the rubluen hose eonnected to it) into the borehole on the rable.

7. When the "utting shoe has roalded the bottom of the borrhole, ehere the denth 
and make a mark on the ("at)le to ent. above the erdge of the casing.

8 . Drive the rore barrel 40 ' $m$. into the undisturberd ground with the weight.

9. Pump up the pressure in the air line and thereby close off the outflow onenings in the sampler head and, if using cutting shoc 1 , the underside of the core barrel.

10. Haul the apparatus up, at the same time maintaining the overpressure. In case the water column in the borchole is higher than $10 \mathrm{~m}$, the pressure during the raising of the apparatus must be decreased, otherwise the maximum permissible pressure in the lines will be exeeded.

11. Upon arrival at the land surface, the eutting shoe is uncoupled and, in case cutting shoe $A$ is used, a little of the sample is immediately removed and the sample tube plugged with a cork. The pressure is thereupon lifted and air can cuter the sampler head above. The sample tube is caught or is removed from the eore barrel with a draw hook.

\section{CARE OF SAMPLLE AN1) TRANSPORTATION OF THE} APPARATUS

In order to protect from drying out, the sample tube, immediately after removal from the cor barrel, is treated on bottom and top with a film composed of a mixture of paraffin and vaseline.

For trassporting the whole coring rig, a small two-wheeled trailer is fitted out and a large box, big enough for 100-sample tubes, is placed upon it. 'This box is lined with a layer of foam rulsher' in order to limit vibration as much as possible during travel.

Up to tho time when they an be studied, the sumples are kept in a refrigerator under a eonstant tomperature of $2^{\circ} \mathrm{C}$. and a high hunidity to prevent their drying out.

\section{SOME RESULTS OF CORE SAMIPLING}

Figures 3 and 4 show some results from rore samples assembled with the help of the abovedescribed apparatus from different deposits in The Netherlands. Wach core is designated by a letter with a serial number, and after that is given the deptl from which the core was taken (in moters bevew land surfice). The hydraulio: condurtivities in the vertical $\left(k_{*}\right)$ direction and in some casses in the horizontal $\left(k_{h}\right)$ direction ats measured in the laboratory are given above earh sample (in meters per (day).

Figure 3 shows the longitudinal sections of cores from a coarse (bearing some fine-gravel) Young Pleistocene Rline deposit from the eastern part of The Netherlands. Mierostruetures barely appear in these wet cores. In general, a much clearer picture of these structures is obtained if "lak films" (lacquer prels) are made from these cores.

Figure 4 shows the longitudinal soctions of cores in wet rondition from fine sandy to clayey Holocene tirlal flat deposits from the western part of the country. The fine laninations, originating from alternating depesition of thin to very thin 'lay and sand layers, show up clearly.

\section{SUMMARY}

A now model core alp)aratus, designed for taking undisturbed samples in deep boreholes, is described, and results olstained with its use are illustrated by a few examples. With the apparatus, through the use of two different coring shoes, complete core simples can readily be taken from all doposits insofar as they do not consist of coarse grare'l.

By alplication of the flush boring method, it is of ten possible in some lithologically favorable seretions to gain considerable time.

The samples taken with this apparatus make it possible to give geological and hydrological investigations a eonsiderably greater aceuracy.

\section{RHFERENCES}

(1) BeL1), R. BA DE 1953 Method of Sampling in Santly Laters Below the (Grouml) WaterT'able. Soil Mech. Lab., l)elft.

(2) Bishop, A.W. 1948 A new sampling tool for use in cohesionless sands below groundwater level. Geotechnique 1:2.

(3) Hvoris,ay, M. J. 1949 Substrface Exploration and Sampling of Solls for Cinil Enginering Purposes. Waterwiys Expt. Sta., Virkislurg, Miss.

(4) Kugmaxi, W., Katstexil a, T., A.jp Wager, (). 1950) Soil sampler with metal foils. Proc. Roy. Swed. Geotechn. Inst,, vol. 1. 